\title{
"AJUDE AÍ DOUTOR!" PODER, HEGEMONIA E COOPTAÇÃO NA BIG PHARMA À LUZ DA ANÁLISE CRÍTICA DO DISCURSO
}

"HELP, DOCTOR!" POWER, HEGEMONY AND COOPTATION AT BIG PHARMA IN LIGHT OF CRITICAL DISCOURSE ANALYSIS

\section{Raquel de Souza Corrêa', Márcio Moutinho Abdalla²}

RECEBIDO EM: 25/02/2020 | ACEITO EM: 23/07/2020

DOI: $10.5902 / 2317175844522$

\section{RESUMO}

Por intermédio de estratégias mercadológicas, a indústria farmacêutica vem cooptando e convencendo a classe médica à prescrição de medicamentos de seus laboratórios, em detrimento de outras alternativas. Percebe-se, portanto, mais do que uma relação assimétrica entre o complexo médico-industrial (aqui tratado como big pharma) e a sociedade, mas uma relação de poder entre esses atores e a consequente mercadificação da saúde. Diante disso, sobretudo em tempos que tanto se depende deste setor, este trabalho tem como objetivo analisar se as práticas empresariais utilizadas pelos representantes da indústria farmacêutica respeitam às normas estabelecidas na regulamentação vigente. Concluiu-se, a partir da Análise Crítica do Discurso que os representantes farmacêuticos entrevistados possuem parcial ou total desconhecimento sobre uma das principais resoluções que rege as atividades do cargo. Assim, observou-se que tais representantes não formulam suas estratégias de cooptação e/ ou convencimento em concordância com o estabelecido na regulamentação, o que possibilita a existência de comportamentos que, mesmo por desconhecimento, seriam compreendidos como antiéticos.

Palavras-Chave: Cooptação; Poder; Estratégia empresarial; Análise crítica do discurso; Indústria farmacêutica

1 ORCID iD: https://orcid.org/0000-0002-2483-2405

Lattes: http://lattes.cnpq.br/3043984121620650. Universidade Federal Fluminense. Brasil 2 ORCID iD: http://orcid.org/0000-0002-2607-1021

Lattes: http://lattes.cnpq.br/4524218198273943. Universidade Federal Fluminense. Brasil 
"AJUDE AÍ DOUTOR!" PODER, HEGEMONIA E COOPTAÇÃO NA BIG PHARMA À LUZ DA ANÁLISE CRÍTICA DO DISCURSO

\begin{abstract}
Through marketing strategies, the pharmaceutical industry has been co-opting and convincing the medical profession to prescribe drugs from their laboratories, to the detriment of other alternatives. Therefore, it is perceived more than an asymmetrical relationship between the medical-industrial complex (here treated as big pharma) and society, but a power relationship between these actors and the consequent health marketing. Given this, especially in times that are so dependent on this sector, this paper aims to analyze if the business practices used by the representatives of the pharmaceutical industry comply with the rules established in current regulations. It was concluded from the Critical Discourse Analysis that the pharmaceutical representatives interviewed have partial or total ignorance about one of the main resolutions that governs the activities of the position. Thus, it was observed that such representatives do not formulate their strategies of co-optation and / or persuasion in accordance with the established in the regulation, which enables the existence of behaviors that, even unknowingly, would be understood as unethical.
\end{abstract}

Keywords: Cooptation; Power; Business strategy; Critical discourse analysis; Pharmaceutical industry

\title{
1 Introdução
}

Dentre os setores que mais prosperam no cenário econômico mundial, a indústria farmacêutica tem se destacado, essencialmente, em razão do expressivo número de vendas e a elevada lucratividade nos últimos anos (BASTOS, 2005; PORTAL BRASIL, 2016). Essa rentabilidade, em sua maioria, é fruto dos elevados investimentos em estratégias mercadológicas (URDAN; URDAN, 2013), corroborando a estratégia empregada por laboratórios farmacêuticos. Anualmente, os laboratórios farmacêuticos investem bilhões de dólares em Pesquisa e Desenvolvimento (P\&D) e em ferramentas de promoção, com a finalidade de ampliarem seu market share (DAS, 2011). Buscando adequar-se melhor a uma economia globalizada e a um mercado com características competitivas e inovadoras como o da indústria farmacêutica, torna-se necessário uma eficaz aplicação de estratégias mercadológicas. Sendo assim, é comum o uso de estratégias de promoção para ampliar e fortalecer a relação entre classe médica e indústria farmacêutica (CARVALHO; TEIXEIRA, 2002).

Contudo, os investimentos destinados aos mecanismos de promoção demonstram que a saúde tem sido tratada como mercadoria e, portanto, objeto de consumo, evidenciando a mercadificação de tudo (ABDALLA, 2016) - mais precisamente a medicalização da saúde (BLANK; BRAUNER, 2009), possibilitando a abertura de discussões sobre aspectos éticos das estratégias de mercado adotadas pela indústria farmacêutica para alcance dos objetivos empresariais (WAZANA, 2000; KOMESAROFF; KERRIDGE, 2002; MOLINARI; MOREIRA; CONTERNO, 2005). A mercantilização da saúde retrata a lógica neoliberal, onde os interesses de mercado prevalecem até mesmo sobre o bem-estar dos indivíduos (DOS SANTOS, 2013), sobretudo em tempos que tanto se depende do setor de saúde. 
Como forma de regulamentar os mecanismos de promoção adotados pela indústria farmacêutica, a Agência Nacional de Vigilância Sanitária (ANVISA) estabeleceu a Resolução da Diretoria Colegiada (RDC) N 96, de 17 de dezembro de 2008. A diretoria da ANVISA é composta por cinco integrantes que, em um sistema de colegiado, tomam decisões pertinentes à regulação de medicamentos. Dentre os muitos pontos discutidos, a resolução proíbe a oferta de brindes, benefícios e vantagens à classe médica, evitando assim que esse fator seja um critério na escolha do medicamento a ser prescrito (DANA; LOEWENSTEIN, 2003; KATZ; CAPLAN; MERZ, 2003, ANVISA, 2008).

Dada a existência da relação assimétrica de poder (GULATI; SYTCH, 2007) entre complexo médico-industrial e sociedade, e as consequentes tratativas propostas pela RDC $N^{\circ} 96 / 2008$, o objetivo dessa pesquisa é analisar se as práticas empresariais utilizadas pelos representantes da indústria farmacêutica atendem ao estabelecido na RDC $n^{\circ} 96 / 2008$. Em outras palavras, desejamos verificar se há situações em que as organizações farmacêuticas não respeitam a resolução, seja como forma de cooptação/convencimento de atores para atingir seus objetivos empresariais, ou para outros fins a serem identificados.

Observa-se na conjuntura econômica atual a mercadificação de tudo, inclusive a da saúde, em que a patologia tem sido tratada como mercadoria, e, portanto, oportunidade de negócio para o complexo médico-industrial. A relevância da pesquisa está em proporcionar reflexões sobre a distinção de valores atribuídos à saúde, tanto por parte da sociedade, quanto por parte da classe médica e da indústria farmacêutica. Estas reflexões objetivam despertar nos indivíduos melhor entendimento sobre as práticas empresariais das organizações e a consequente mercadificação da saúde.

\section{Fundamentação Teórica}

\subsection{Estratégias Direcionadas à Atividade de Vendas}

A interação empresa-consumidor é, em geral, norteada por interesses mercadológicos, com destaque para o retorno sobre investimento, corroborando o conceito de racionalidade instrumental. Busca-se potencializar e racionalizar ao máximo o uso dos recursos organizacionais visando, essencialmente, o alcance dos interesses de mercado, a partir da lógica capitalista de maximização dos resultados (LIMA; AMORIM; FISCHER, 2015; BARROS; CARRIERI, 2015).

No complexo médico-industrial há, em linhas gerais, dois tipos de mercado: a classe médica, que atua no mercado de serviços; e a indústria farmacêutica, que atua no mercado de produtos. Esses dois mercados associam-se para atender à sociedade, contudo, há outros interesses por trás dessa assistência (MOLINARI; MOREIRA; CONTERNO, 2005; RIOS; MORAES, 2013), que se impulsionaram com o advento da política econômica neoliberal na América Latina, mais precisamente no Brasil em 1990 (RIBEIRO; JURUENA, 2013). 
"AJUDE AÍ DOUTOR!" PODER, HEGEMONIA E COOPTAÇÃO NA BIG PHARMA À LUZ DA ANÁLISE CRÍTICA DO DISCURSO

O neoliberalismo é caracterizado, basicamente, por dois aspectos, o livre mercado e a mínima intervenção do Estado (HARVEY, 2008). Contudo, o Estado não deve ser visto como um obstáculo, e sim como parte do sistema econômico (BRESSER-PEREIRA, 2009). O neoliberalismo promoveu o livre mercado, acirrando-se, dessa forma, a busca por lucro nas organizações. Com a indústria farmacêutica não foi diferente, tendo parte dela optado pela estratégia de investimento em P\&D, com fins de obter melhor posicionamento.

Os altos valores investidos na indústria farmacêutica são basicamente em P\&D e estes podem demorar muitos anos até que um medicamento seja concluído, comercializado, e então comece a gerar retorno financeiro para a organização. Com isso, a indústria necessita que este retorno supere o investimento já realizado e possibilite a continuação de investimento em P\&D (REIS, et al., 2009). A fase de crescimento do produto no mercado é a que, em geral, mais se obtém retorno financeiro durante seu ciclo de vida (URDAN; URDAN, 2013), conforme pode ser observado na figura 1, que ilustra o setor de medicamentos.

Figura 1 - Ciclo de vida do produto

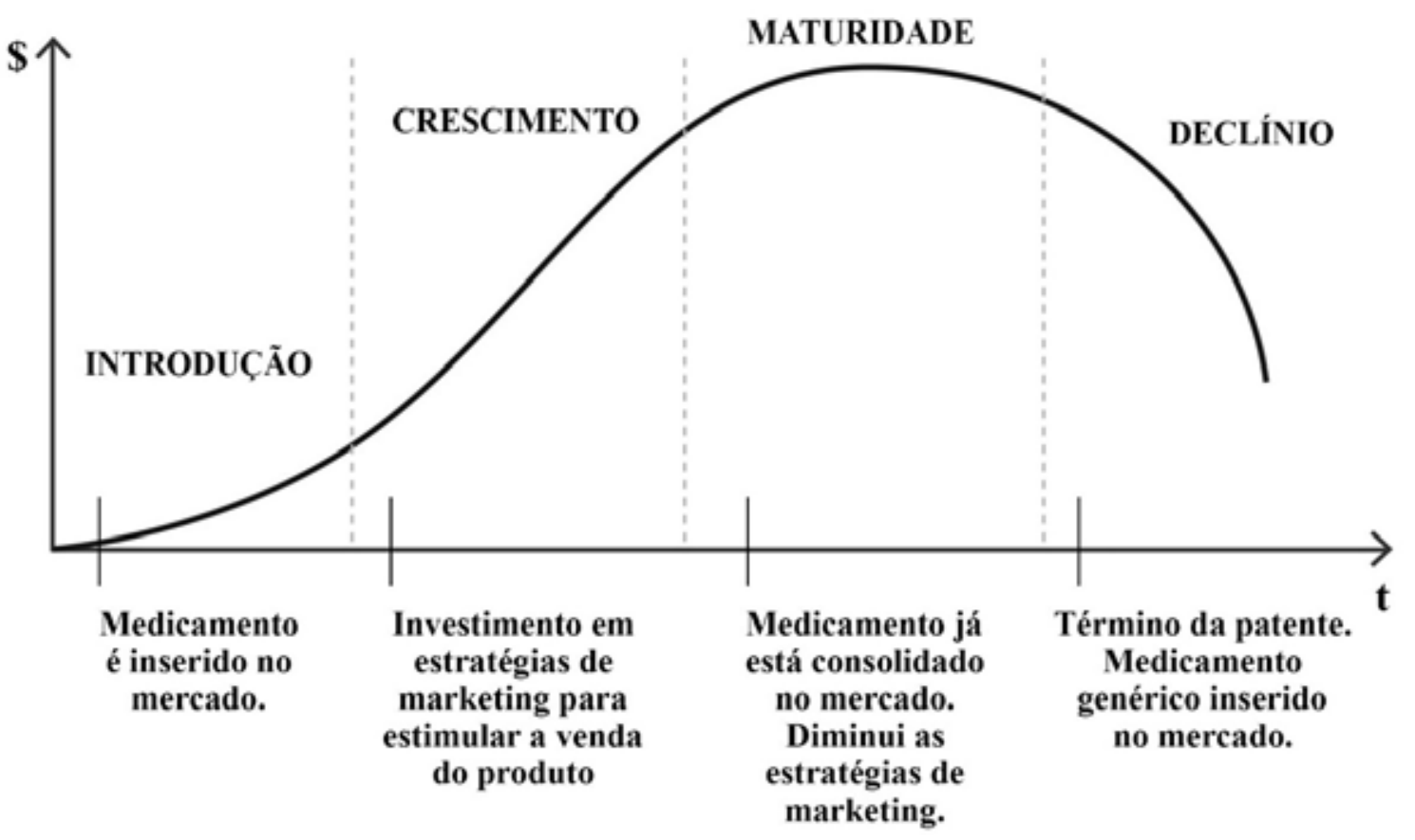

Fonte: Elaborado pelos autores com base em Levitt (1965).

Durante os primeiros 20 anos em que o medicamento é comercializado, a Lei $\mathrm{N}^{\circ} 9.279$ (Lei das Patentes), de 14 de maio de 1996, permite que os donos da propriedade industrial patenteada sejam os únicos beneficiários do retorno do produto lançado no mercado (BASTOS, 2005), podendo assim recuperar os gastos em P\&D. Além da Lei das Patentes, a indústria farmacêutica utiliza estratégias mercadológicas, como a estratégia de diferenciação de produtos, 
em que a indústria produz pesquisas sobre componentes para o lançamento de novos medicamentos no mercado, e a estratégia de investimento em ferramentas de marketing (REIS et al., 2009). De acordo com esse contexto, nota-se o alto investimento da big pharma (grande indústria farmacêutica) em estratégias mercadológicas para ampliação das vendas, buscando obter maior rentabilidade (BRANDÃO, 2015).

O expressivo número de empresas atuantes no mercado farmacêutico tem ampliado a competitividade do setor. Como forma de estimular a venda de seus produtos, as organizações necessitam criar uma relação duradoura com seus clientes (BRETT; BURR; MOLOO, 2003). Visando alcançar tal objetivo, a indústria farmacêutica faz uso de ferramentas de promoção na relação com seu principal canal, a classe médica. Dada a importância dos médicos na geração de demanda, torna-se intensa a propaganda e o esforço de venda a eles destinado (CONNORS, 2009; RAMOS, 2010).

Visto que a promoção de vendas é direcionada à classe médica, os representantes farmacêuticos realizam visitas a diferentes consultórios médicos com o intuito de apresentar seus medicamentos e estimular que o médico os prescreva (BLACK, 2005; RAMOS, 2010). O que mantém essa relação de poder entre indústria farmacêutica e classe médica são os incentivos oferecidos pela indústria como, amostras grátis, brindes, patrocínio de congresso e cursos (MOLINARI; MOREIRA; CONTERNO, 2005; CORRÊA; OLIVEIRA, 2008), contrariando a normatização preconizada pela RDC N 96/2008.

A utilização dessa estratégia mercadológica para a ampliação da venda de medicamentos tem sido pauta de discussão ética, sinalizando a mercadificação da saúde. Essa consequência deve-se ao atual modelo de governança, baseado no benefício de poucos em detrimento de muitos, juntamente à distorção de princípios éticos nessas esferas, atingindo diretamente as atividades das organizações e o bem-estar da sociedade. Dessa forma, intensifica-se a busca por ações éticas nessa relação de poder do complexo médico-industrial (KOMESAROFF; KERRIDGE, 2002; MASSUD, 2010; RIOS; MORAES, 2013).

\subsection{Aspectos Éticos em Negócios}

As organizações estão inseridas em ambientes moldados por questões legais, políticas, econômicas, sociais e ambientais. No Brasil, embora existam amplos esforços em prol do modelo neoliberal, o Estado regulador é ainda presente. É imprescindível a elaboração e efetiva aplicação de normas jurídicas com a finalidade de regular as atividades das grandes corporações, que se tornaram mais competitivas e complexas, sobretudo em setores mais sensíveis, a exemplo da saúde. Assim, evidencia-se a importância da ética em negócios e da legislação, sendo possível atenuar possíveis práticas questionáveis.

A regulação das atividades organizacionais visa, em linhas gerais, assegurar a proteção das próprias empresas, dos consumidores e da sociedade. Dada 
"AJUDE AÍ DOUTOR!" PODER, HEGEMONIA E COOPTAÇÃO NA BIG PHARMA À LUZ DA ANÁLISE CRÍTICA DO DISCURSO

essa finalidade, a ANVISA é responsável pela elaboração de inúmeras resoluções. Dentre elas, destacamos a RDC $n^{\circ}$ 96/2008, que "dispõe sobre a propaganda, publicidade, informação e outras práticas cujo objetivo seja a divulgação ou promoção comercial de medicamentos" (ANVISA). Contudo, percebe-se que a realidade tem mostrado ser diferente das práticas recomendadas (RIBEIRO; JURUENA, 2013), apesar de os princípios éticos nas organizações e da existência de instrumentos legais, como o estabelecido pelo Art. $5^{\circ}$ da RDC $n^{\circ}$ 96/2008:

As empresas não podem outorgar, oferecer, prometer ou distribuir brindes, benefícios e vantagens aos profissionais prescritores ou dispensadores, aos que exerçam atividade de venda direta ao consumidor, bem como ao público em geral.

Deve-se deixar claro que o propósito desta pesquisa não é debruçar sobre as discussões a respeito da ética corporativa de um modo geral, mas sim abordar o que é tratado como ético a partir da aludida resolução. A palavra ética está presente no senso comum, porém seus significados são superficialmente compreendidos. Ética é de origem grega e refere-se ao conjunto de valores e princípios que norteiam a conduta dos indivíduos (CORTELLA, 2015; COPEINSKI; APPA, 2016). Com isso, o que irá caracterizar um indivíduo ou uma organização como ético ou antiético é o ato de seguir ou não valores, princípios, normas e costumes de determinada sociedade. Entende-se que a ética não existe somente para indivíduos, mas também para organizações. Por possuir função normativa, a ética está presente nas organizações por intermédio dos códigos de ética, buscando impedir ações questionáveis por parte das organizações e de seus representantes (MARCONDES, 2007).

Em uma economia neoliberal, é comum diversas organizações estabelecerem que indivíduos e seus desejos sejam objeto de negociação, mascarando a percepção ética de suas atitudes. De acordo com Cortella (2015) é a descoisificação, ou seja, tratar o indivíduo como outro e não como objeto, que irá permitir ter visão ética.

O consumismo alcançou um patamar em que o bem-estar dos indivíduos e da sociedade, muitas vezes, é pseudo valorizado, visto que o mercado cria a ideia de necessidade por algo, levando ao consumo de produtos que supostamente iriam suprir aquela carência. (MANCEBO et al., 2002). Na esfera farmacêutica, a medicalização da saúde (BLANK; BRAUNER, 2009) tem se agravado, principalmente, pelos interesses empresariais da indústria e da classe médica.

Dado o crescente processo de medicalização da saúde, a sociedade tem questionado, ainda de forma incipiente, se as ações praticadas pela indústria farmacêutica e pela classe médica estão de acordo com princípios éticos (CORRÊA; OLIVEIRA, 2008), como por exemplo, a prescrição de um medicamento novo, mais caro e com similar eficácia de outro já existente. Esse questionamento pode ser motivado pelos benefícios que a classe médica obtém ao manter acordos com laboratórios, demonstrando o poder existente nessa relação e os impactos na sociedade (MOLINARI; MOREIRA; CONTERNO, 2005). 
Busca-se entender o que é considerado ético ao referir-se às atividades de organizações que objetivam lucro (URDAN, 2005). Como a ética diz respeito ao conjunto de princípios que orientam a conduta dos indivíduos e organizações, caso estes utilizem de estratégias que violem regulações, possivelmente estariam tendo atitudes não-éticas.

O panorama atual indica que as organizações tendem a implementar ações mercadológicas que respeitem, com maior efetividade, aspectos éticos, devido ao aumento de discussões nessa esfera (CORRÊA; OLIVEIRA, 2008). Porém, o dilema existente é referente à repercussão das discussões éticas enfrentadas, se elas motivarão transformações na conduta da indústria farmacêutica e da classe médica, ou se permanecerão somente como uma tendência.

\subsection{O Poder de Cooptação e Influência da Indústria Farmacêutica}

São crescentes as pesquisas que analisam como as organizações modificam o ambiente em que estão inseridas, ou seja, o modo como as organizações influenciam a economia, a política, e até mesmo os instrumentos legais (GULATI; SYTCH, 2007; BARLEY, 2010; FLEMING; SPICER, 2014). Dessa forma, nota-se que as grandes corporações são capazes de alterar cenários de acordo com seus interesses empresariais, destinando cada vez mais recursos para a manutenção de seu poder sobre outros atores (ANDERSON; BERDAHL, 2002; FARIA; ABDALLA, 2014), a exemplo da própria sociedade.

Tal situação é explicada em razão do caráter vital que o poder possui para as organizações manterem vantagem competitiva no mercado em que atuam (FLEMING; SPICER, 2014). Compreende-se que o fundamento da política econômica neoliberal amplia o campo de atuação das organizações, tornando-se árduo o controle das ações empresariais. Diante dessa perspectiva, observam-se práticas de manipulação e cooptação de atores, como o governo e outras instituições, disseminando assim o sentido negativo do poder organizacional. Contudo, assim como as práticas de cooptação e manipulação podem ser vistas com clareza em diversas circunstâncias, há situações em que o poder das organizações se dá de maneira sutil e quase imperceptível, dado que as práticas podem ocorrer também em seu ambiente externo (BARLEY, 2010; FLEMING; SPICER, 2014).

As organizações influenciam diversas forças de mercado a seu favor (VIEIRA; MISOCZKY, 2003) a exemplo da indústria farmacêutica, que é conhecida por seu crescimento econômico, e também por ser um setor extremamente poderoso, tendo capacidade de influenciar e de modificar seu ambiente. Assim, as mesmas têm direcionado esforços e adotado estratégias de cooptação e manipulação como forma de gerir o ambiente, e com isso, minimizar as ameaças de mercado (ABBASI; SMITH, 2003; APPLBAUM, 2006; SANVITO, 2012).

A cooptação da classe médica ocorre, em grande parte, por meio da oferta de brindes, oferta de "agrados", como por exemplo, pagamento de jantares e 
"AJUDE AÍ DOUTOR!" PODER, HEGEMONIA E COOPTAÇÃO NA BIG PHARMA À LUZ DA ANÁLISE CRÍTICA DO DISCURSO

viagens, e patrocínio de congressos (MARQUES FILHO, 2010), sendo tais práticas proibidas conforme dispõe a RDC $n^{\circ} 96 / 2008$. Contudo, o patrocínio de congressos não é necessariamente proibido pela ANVISA, desde que o mesmo não seja condicionado à prescrição de medicamentos, algo complexo de ser controlado.

Embora a classe médica defenda não ser influenciada pelas estratégias de cooptação da indústria farmacêutica (MARQUES FILHO, 2010), estudos constatam que estas estratégias podem influenciar também (i) pesquisadores, para o desenvolvimento de medicamentos que sejam do interesse da indústria farmacêutica, (ii) agências reguladoras, com o intuito de obter vantagens e mais liberdade de atuação, (iii) farmácias, as quais possuem o papel na efetivação das vendas dos medicamentos, e (iv) consumidores, que por meio das propagandas são estimulados a consumirem (MENDONÇA; CAMARGO, 2012).

Ao analisar com maior profundidade as estratégias de cooptação utilizadas pela indústria farmacêutica, torna-se explícita a relação assimétrica existente entre o complexo médico-industrial e a sociedade, evidenciando a fragilidade ética nesse mercado. Tal fato pode ser motivado pela falta de controle e monitoramento das regulações, acarretando em um possível não cumprimento das mesmas (SILVA, 2010).

Segundo Santos, Bliacheriene e Ueta (2011), o poder da indústria farmacêutica expande-se basicamente devido a dois fatores: a precariedade das agências reguladoras e a frágil instrução ética dos agentes cooptados. Assim, esses fatores têm assegurado maior "liberdade" para a indústria executar sua estratégia de cooptação, impactando direta ou indiretamente no bem-estar dos indivíduos. Contudo essa liberdade outorgada é exclusiva de uma elite privilegiada, pois o restante da sociedade não é livre, pelo contrário, está sujeito às práticas de cooptação (HARVEY, 2008).

\subsection{O Poder do Discurso}

O cenário político-econômico neoliberal vem impactando e modificado fortemente aspectos culturais e sociais. Altera-se também a linguagem empregada e os discursos nas relações sociais, em que há o dominante e o dominado, tornando explícita a relação de poder. A análise crítica do discurso (ACD) proposta por Norman Fairclough é uma abordagem considerada teórico-metodológica, de essência crítica, que objetiva analisar os significados além do limite do registro textual. Ao correlacionar linguagem e relações sociais, a ACD visa identificar ideologias e relações de poder (BRANDÃO, 2004; SILVA; GONÇALVES, 2017; ABDALLA; ALTAF, 2018) que permeiam os textos e suas condições de produção. Os processos sociais de dominação discursiva ocorrem sob muitas roupagens, por meio dos discursos políticos, midiáticos, educacionais, profissionais e organizacionais, que controlam conhecimentos e opiniões das pessoas (DIJK, 2016). Segundo o autor, "a forma moderna de abuso de poder é o controle da mente (p.736). 
As ideologias são intrínsecas na produção do discurso dos indivíduos, de tal maneira que, sem perceberem esse jogo de poder, são levados à reproduzirem ideologias que são nocivas a eles e à sociedade. Essas ideologias do discurso apresentam-se de forma opaca, com o intuito de facilitar a dominação (IRIGARAY; CUNHA; HARTEN, 2016; SILVA; GONÇALVES, 2017). O discurso dos representantes farmacêuticos para com a classe médica, assim como o da classe médica para com seus pacientes está repleto de aspectos ideológicos, que constituem a base para as lutas hegemônicas (FAIRCLOUGH, 2001; SILVA; GONÇALVES, 2017). Essas disputas entre classes dominadas e dominantes revelam a necessidade de construir, manter ou romper relações de poder (FAIRCLOUGH, 2001).

A prática discursiva das organizações objetiva influenciar o desempenho de seus colaboradores devido a sua inserção em uma esfera maior, com aspectos hegemônicos e ideológicos, isto é, a esfera social (IRIGARAY; CUNHA; HARTEN, 2016). Ao analisar a indústria farmacêutica, percebe-se que esta influencia o comportamento dos representantes farmacêuticos que, por sua vez, almejam cooptar a classe médica, a partir do discurso corporativo, objetivando a maximização de prescrições dos medicamentos que promovem. A análise crítica do discurso permite desvelar o poder de dominação e as ideologias implícitas nos discursos organizacionais, possibilitando maior nível de consciência dos indivíduos, em relação aos aludidos processos de dominação (SILVA; GONÇALVES, 2017).

\section{Método de Pesquisa}

Essa pesquisa pode ser classificada como aplicada, qualitativa e exploratória. Aplicada por ser direcionada à criação de conhecimento e aplicação prática em contexto específico. Qualitativa dado que busca interpretar fenômenos e atribuir significados. E exploratória, pois visa gerar maior proximidade com o problema em questão, auxiliando na criação de hipóteses (GIL, 2002; MORESI, 2003). O corpus da pesquisa é composto de dados primários, ou seja, a coleta foi feita especificamente para a pesquisa em questão. Os dados foram coletados por meio de entrevistas estruturadas, realizadas com representantes da indústria farmacêutica.

O roteiro foi estruturado com questões pertinentes ao tema em estudo e às lacunas existentes no mesmo. Com o intuito de não dispor de um conjunto de dados muito extenso (FAIRCLOUGH, 2001), optou-se por entrevistar quatro representantes de uma indústria farmacêutica nacional de grande porte - apesar de a amostra ser considerada pequena para pesquisas quantitativas, na Análise Crítica do Discurso, que é uma abordagem teórico-metodológica predominantemente qualitativa e interpretativa, considera-se este corpus de dados relevante e representativo (NOGUEIRA, 2001). A empresa ocupa hoje um dos primeiros lugares no ranking das organizações com maior valor de mercado. O primeiro entrevistado convidado foi quem indicou os demais sendo, portanto, escolhidos por conveniência, por meio do modelo snow ball. 
"AJUDE AÍ DOUTOR!" PODER, HEGEMONIA E COOPTAÇÃO NA BIG PHARMA À LUZ DA ANÁLISE CRÍTICA DO DISCURSO

Este modelo consiste em uma técnica amostral não probabilística, utilizada quando o pesquisador possui dificuldade de acesso aos indivíduos que representam o objeto de estudo. Dessa forma, um primeiro indivíduo é convidado para participar da pesquisa, que passa a indicar novos participantes, e assim sucessivamente, compondo a amostra necessária para execução do estudo (VINUTO, 2014). As entrevistas foram integralmente transcritas para posterior análise à luz da abordagem teórico-metodológica da ACD.

De acordo com a abordagem de Fairclough (2001), o discurso não é constituído somente de elementos textuais, mas também de aspectos políticos e ideológicos. Dessa forma, compreendendo a proposta da ACD, de analisar os significados além do limite do texto, essa abordagem foi escolhida visando explorar nos discursos dos representantes farmacêuticos aspectos que, alinhados à pesquisa bibliográfica demonstrassem as estratégias utilizadas pela indústria para atingir seus objetivos empresariais.

Norman Fairclough propõe a Concepção Tridimensional do Discurso, um modelo que engloba texto, prática discursiva e prática social como as três dimensões do discurso, conforme figura 2.

Figura 2 - Concepção Tridimensional do Discurso

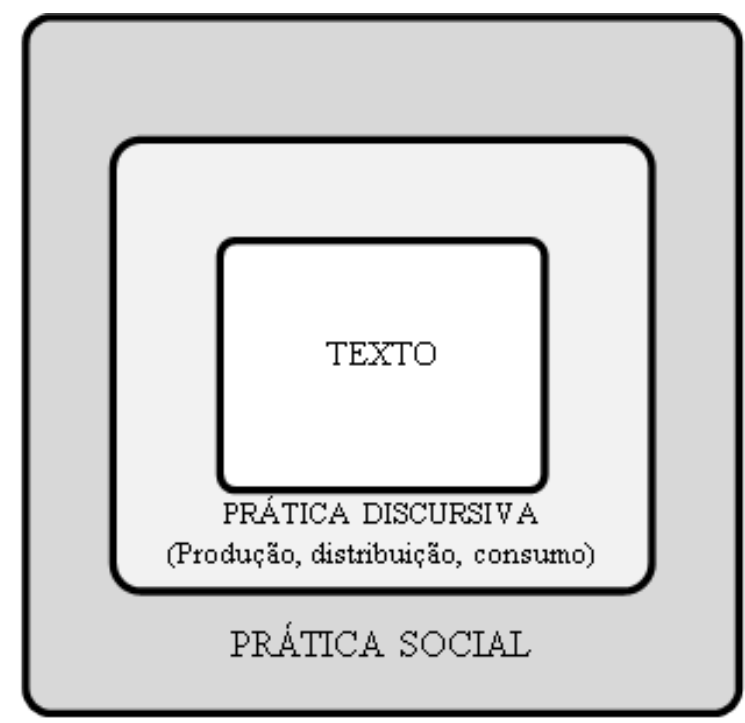

Fonte: Fairclough, N. (2001). Discurso e mudança social. Brasília: Universidade de Brasília.

A primeira aborda a descrição dos aspectos textuais, como vocabulário, gramática, coesão e estrutura textual. Já a prática discursiva compreende a produção, distribuição e interpretação textual como processos relacionados ao âmbito social; analisa-se aí também coerência, intertextualidade e interdiscursividade. A Coerência refere-se ao equilíbrio de um discurso, obtido a partir da relação lógica entre as ideias, sendo capaz de criar um texto harmônico e que faça sentido. Já a intertextualidade aborda a relação existente entre discursos, isto é, a construção de um texto a partir de trechos de outros 
textos. Este último é tido como um conceito semelhante à interdiscursividade (ABDALLA; ALTAF, 2018). Por fim, o intradiscurso, é conceituado como " 'fio do discurso' do sujeito, é, a rigor, um efeito do interdiscurso sobre si mesmo, uma 'interioridade' inteiramente determinada como 'tal do exterior'." (PÊCHEUX, 1988, p.154). De acordo com o modelo, a dimensão textual está contida na dimensão da prática discursiva, e esta está contida em uma dimensão maior: a prática social, que está relacionada aos aspectos ideológicos e hegemônicos (FAIRCLOUGH, 2001; SILVA; GONÇALVES, 2017).

Para o pesquisador analisar as questões por ele formuladas e obter conclusões pertinentes à análise é primordial a construção do dispositivo analítico. Esta é dada por meio do exercício da leitura e interpretação (ORLANDI, 2015). A análise do discurso não se limita ao texto, abrange o discurso como prática social, em que deve ser analisada a linguagem juntamente ao contexto histórico (SILVA; GONÇALVES, 2017).

É necessário salientar que a seleção dos trechos para posterior análise foi norteada por um processo sistemático durante todo o procedimento. Os trechos foram agrupados em categorias analíticas determinadas com base no roteiro de entrevista, que por sua vez, foi norteado pela teoria e pela questão de pesquisa. Além disso, parte das análises foi realizada junto a um grupo de pesquisadores de $A C D$, reforçando a validade das mesmas, por meio de triangulação entre pares.

A Análise Crítica do Discurso não possui um roteiro fixo e predeterminado para desenvolvimento das análises. Nesse sentido, para melhor elucidação de como as análises foram construídas utilizou-se do framework metodológico elaborado por Abdalla e Altaf (2018), conforme a figura 3. 


\begin{tabular}{|c|c|c|}
\hline $\begin{array}{l}\text { PARTE 1 } \\
\text { Definições } \\
\text { iniciais } \\
\text { (Dados) }\end{array}$ & $\begin{array}{l}\text { - Definição do contexto e problemática; } \\
\text { - Definição do objetivo; } \\
\text { - Definição dos dados a serem usados (seleção do corpus). }\end{array}$ & $\begin{array}{c}\text { Definição das } \\
\text { Unidades de } \\
\text { Análise }\end{array}$ \\
\hline $\begin{array}{l}\text { PARTE 2 } \\
\text { Análises } \\
\text { preliminares }\end{array}$ & $\begin{array}{l}\text { - Coleta dos dados (primeira análise preliminar); } \\
\text { - Transcrição (segunda análise preliminar); } \\
\text { - Organização dos dados e análise preliminar aprofundada: } \\
\text { ○ Leitura flutuante de todo o corpus; } \\
\text { ○ Organização em categorias definidas a priori. }\end{array}$ & $\begin{array}{l}\text { Organização } \\
\text { em categorias } \\
\text { definidas } a \\
\text { priori }\end{array}$ \\
\hline \multirow[t]{3}{*}{ PARTE 3} & $\begin{array}{l}\text { Análise Textual: } \\
\text { Vocabulário, Gramática, Coesão e Estrutura Textual. }\end{array}$ & \multirow{2}{*}{$\begin{array}{l}\text { Definição das } \\
\text { Unidades de } \\
\text { Análise }\end{array}$} \\
\hline & $\begin{array}{l}\text { Análise das Práticas Discursivas: } \\
\text { Produção, Distribuição e Consumo dos discursos. }\end{array}$ & \\
\hline & $\begin{array}{l}\text { Análise da Prática Social: } \\
\text { Aspectos ideológicos e hegemônicos. }\end{array}$ & $\begin{array}{l}\text { Desvelar de } \\
\text { Categorias } \\
\text { emergentes }\end{array}$ \\
\hline & RESULTADOS & \\
\hline
\end{tabular}

Figura 3 - Framework proposto para Análise Crítica do Discurso Fonte: Abdalla e Altaf (2018).

\section{Análise dos Resultados}

4.1. Opinião dos Representantes Farmacêuticos em Relação à RDC N 96/2008

Buscou-se com as entrevistas explorar qual o entendimento dos representantes farmacêuticos em relação à RDC N 96/2008, e com isso, analisar se as indústrias atendiam aos aspectos estabelecidos por esta.

Percebeu-se que os entrevistados tinham em comum escasso conhecimento no que se refere à $\mathrm{RDC}$, resolução diretamente relacionada à prática da profissão em questão, que "dispõe sobre a propaganda, publicidade, informação e outras práticas cujo objetivo seja a divulgação ou promoção comercial de medicamentos" (ANVISA), como é apontado no discurso de E2: "Essa é uma das principais, mas... ...ela é bem grande, muito detalhada, absurdamente chata (ênfase) [risos]" e de E3: "Eu desconheço" quando questionados sobre a mesma. A aversão é evidenciada ao fazer uso do advérbio de intensidade 'absurdamente', qualificando o adjetivo 'chata', que demonstra, portanto, uma tendência dos representantes entrevistados a colocarem uma das principais regulações da sua área como conhecimento não prioritário, atuando sem ter ciência das normas que regem as atividades de seu cargo quando, na verdade, ela deveria ser um dos principais guias para o exercício de sua rotina. 
As respostas curtas e incisivas podem revelar apatia, ou por real desconhecimento em razão de motivos diversos e não propositais, ou por não quererem se aprofundar no tema abordado intencionalmente. Contudo, em ambos os casos, seja por descuido ou negligência, a estagnação resultante é alarmante, pois de acordo com o Decreto-Lei $N^{\circ} 4.657$, de 4 de setembro de 1942 , Art. $3^{\circ}$ "Ninguém se escusa de cumprir a lei, alegando que não a conhece" (BRASIL, 1942).

4.2. Aspectos das Relações e Negociações com a Classe Médica na Visão dos Representantes Farmacêuticos

É fundamental entender que o trabalho dos representantes farmacêuticos é realizado, em grande parte, junto à classe médica, pois a prescrição de medicamentos é uma função atribuída especificamente a ela. Dessa forma, estes são alvos de um forte trabalho para divulgação de medicamentos, empreendido pela indústria farmacêutica (BOMFIM; PEREIRA, 2004; MOLINARI; MOREIRA; CONTERNO, 2005).

Neste contexto, destaca-se o grande jogo de interesses entre indústria farmacêutica e a classe médica, na qual há uma forte relação de poder, evidenciando as práticas ideológicas de ambas as partes. É então criada uma forte relação de dependência, em que os representantes farmacêuticos produzem um intenso esforço de convencimento para que o médico prescreva o medicamento de seu laboratório, como menciona E2: "Eu tenho que convencer o médico a prescrever um produto pra aquela paciente ir na farmácia e comprar o medicamento".

Esse enfoque na relação entre indústria e médico é confirmado no próprio discurso do E2: "A gente não vai deixar de visitar o médico, que é o meu ganha pão, porque é ele que vai fazer com que o meu produto gire, né?!", e de E1: "Se eu falar qualquer coisa que dê segunda conotação e ele não goste, acaba o assunto ali e pronto", dando a entender que os assuntos durante as conversas existentes entre os médicos e os representantes têm, de fato, peso no processo de decisão do médico, de recomendar um medicamento em função de outro, e que não depende apenas (ou prioritariamente) da habilidade do representante em estabelecer que seu produto ofereça benefícios reais e/ ou diferentes dos concorrentes como aumento do valor e utilidade entregue ao paciente, mas em assuntos outros, que não necessariamente se limitem aos aspectos do remédio em si.

Sendo assim, quanto maior a dependência da indústria farmacêutica em relação à classe médica, maior o poder dos médicos nesse jogo de interesses. Contudo, sabe-se que a indústria farmacêutica possui enorme poder econômico, sendo um dos segmentos que mais cresceu nas últimas décadas. Desse modo, apesar de parecer que há uma parte em desvantagem devido aos arranjos de poder e consequente dependência, a relação entre médico e 
"AJUDE AÍ DOUTOR!" PODER, HEGEMONIA E COOPTAÇÃO NA BIG PHARMA À LUZ DA ANÁLISE CRÍTICA DO DISCURSO

representante não é o único canal disponível à indústria farmacêutica para alcance do seu consumidor-fim (CONNORS, 2009), fazendo com que a fragilidade existente nessa relação em específico não diminua sua capacidade de exercer influência nos agentes que integram seu mercado.

Nesse jogo de interesses, os envolvidos utilizam diversas estratégias visando obter ganhos. Com isso, é notória a intradiscursividade no discurso dos representantes, isto é, a influência do discurso da indústria farmacêutica, pois a preocupação primária no enunciado dos representantes não é o paciente, e sim o alcance dos objetivos comerciais impostos pela empresa. Dessa forma, observa-se nas estratégias dos representantes farmacêuticos forte aspecto de soft power (NYE, 2004; ROSELLE; MISKIMMON; O'LOUGHLIN, 2014), ou seja, a tentativa de atração e cooptação dos médicos por meio de instrumentos intangíveis, como por exemplo, a capacidade de convencer e/ou exercer influência dado um interesse em comum (potencialmente o bem estar dos pacientes), interesses complementares (o médico "precisa" do remédio para auxiliar o processo de recuperação de seus pacientes e o representante "precisa" garantir o giro de seu produto), ou interesses pessoais (vontades, desejos ou aspirações que uma das partes presentes na relação foi capaz de perceber na outra e que tem o poder de interferir de maneira a facilitar a satisfação dos fins almejados, se a outra parte cumprir determinada condição).

Há, então, um empenho para a criação de uma relação amigável com os médicos, pois como relata $\mathrm{E} 1$ :

"A dificuldade de negociação é que se você utilizar algum termo que possa ter uma, como posso dizer [pausa longa], uma segunda interpretação, o médico te dá uma cartada. Uma cartada no sentido de: 'ué, você está querendo que eu faça isso, por que? O que eu vou ganhar com isso?"" (E1).

A percepção que se tem é que o representante já sabe exatamente como agir com a classe médica para atingir seus objetivos e que ambos conhecem a "regra do jogo" e, portanto, o propagandista precisa falar de uma maneira que o enunciado não repercuta de forma "errada". Contudo, o suposto discurso do médico revela-se contraditório, uma vez que se subentende que ele pede algo em troca ao dar uma "cartada", mas ao mesmo tempo o propagandista não pode falar abertamente sobre como esse "algo" é estabelecido e como são arrumados os termos de troca entre as partes. Além disso, o discurso do médico expressa falta de polidez ao fazer indagações diretas e pontuais, mostrando uma postura de superioridade em relação ao representante e, mais do que isso, um comportamento de expectativa, ou seja, o médico também já faz parte da conversa sabendo que pode obter algo a partir dos interesses que percebeu no representante.

Nesse sentido, manifesta-se a questão do ethos descrita por Fairclough (2001), isto é, a associação de características que formam o "eu" e as identida- 
des sociais, pois o médico possui segurança em ser literal e direto por sentir-se superior, mas em momento algum o médico quer que o representante seja direto com ele. Entretanto, é importante analisar o lócus de enunciação, ou seja, de onde se enuncia e de onde se percebe, ambos os lados, dado que este é o discurso do médico na perspectiva do representante farmacêutico.

Este lócus de enunciação é capaz de produzir percepções e efeitos distintos de acordo com o lado em que se está. Entretanto, no jogo de interesses entre indústria farmacêutica e classe médica, estes parecem estar do mesmo lado, como demonstra o discurso de E2:

\begin{abstract}
"A relação com os médicos é uma relação bem interessante, bem legal. Acho que, na verdade, depende muito do que você mostra pro médico, entendeu?! Da segurança que você mostra pra ele, da simpatia, da empatia, tudo isso, acho que envolve muito a relação. $E$ as maiores dificuldades que a gente encontra hoje...[pausa longa] ...é que ainda, sim, é... ...existe a compra dos médicos, ainda existe. A empresa que eu trabalho é uma empresa que não preza por isso. Preza por atender a necessidade daquele paciente. Só que ainda existem algumas empresas que fazem isso, e isso nos traz muitos problemas, porque... [pausa longa] ...muitos médicos são absurdamente éticos, e não aceitam, mas muitos médicos aceitam." (E2).
\end{abstract}

A relação de dependência e postura de inferioridade do representante é evidenciada desde o início do discurso, ao mostrar que precisa conquistar àquele que possui o poder de prescrição de seus medicamentos. A percepção de que a saúde do paciente não é a preocupação primária nessa relação é confirmada quando o entrevistado reconhece a "compra" dos médicos. Pressupõe-se, portanto, a existência de conflitos de interesses entre médicos e representantes, como afirmam Marques Filho (2010) e Massud (2010).

Buscando minimizar o que foi dito, o entrevistado esforça-se em negar que sua empresa não preza pela "compra" dos médicos. O representante fala do lócus de enunciação como um lugar ético, dessa forma, aparentemente distancia-se do problema da "compra" dos médicos. E completa dizendo que 'isso nos traz muitos problemas', entretanto, não é especificado quem está contido em 'nos'. Traz problema para ele representante? Para a indústria farmacêutica? Ou para os pacientes?

O discurso apresenta inúmeras contradições quando, por exemplo, o representante utiliza o advérbio de intensidade 'absurdamente' para qualificar o adjetivo 'ética', dando a entender que alguns indivíduos são mais éticos do que outros. Aponta-se a existência de duas maiorias em uma mesma situação, uma vez que muitos aceitam e muitos não aceitam. Subentende-se, portanto, que a preocupação maior do entrevistado não é em relação à existência de empresas e/ou médicos antiéticos, e sim, os problemas que o seu laboratório pode enfrentar a partir dessas situações. 
"AJUDE AÍ DOUTOR!" PODER, HEGEMONIA E COOPTAÇÃO NA BIG PHARMA À LUZ DA ANÁLISE CRÍTICA DO DISCURSO

Contudo, o mesmo representante, que diz não comprar os médicos, no sentido literal da expressão. Afirma que sua empresa custeia congressos para a classe médica, sendo estes permitidos, conforme a RDC $N^{\circ} 96 / 2008$, desde que não estejam condicionados à prescrição de medicamentos (ANVISA).

"Acontece dos médicos, às vezes, solicitarem congresso... [pausa longa] ...isso eles fazem, e isso a gente trabalha, não, não tem por quê... [pausa longa] ... até porque isso não é, não é... [pausa longa] ...como é que eu falo?! Não tá errado, na verdade você tá investindo na evolução daquele médico, né?! Isso pra ele é bom e pra mim também, porque quando ele entende melhor e ele ter uma visão melhor, também me ajuda na minha argumentação com ele. E como os congressos são todos patrocinados e bancados pela indústria, nós temos condição de mandar alguns médicos pra aperfeiçoar o conhecimento deles". (E2).

Até o momento nenhum discurso dos representantes apresentou essa condicionante, dado que é difícil visualizar esse aspecto no discurso de quem é responsável pela realização de tais eventos. Porém, sabe-se do alto investimento para a realização de congressos, e que dificilmente uma corporação investiria em atividades não rentáveis. Como o próprio entrevistado diz, essa prática é conveniente para ambos os lados desta relação, a classe médica e a indústria farmacêutica, excluindo quem deveria ser o maior beneficiário, o paciente. De acordo com Molinari, Moreira e Conterno (2005), e Corrêa e Oliveira (2008), o patrocínio de congressos é uma das estratégias adotadas pela indústria farmacêutica na cooptação da classe médica. Essa capacidade de a indústria farmacêutica patrocinar e custear congressos, que teoricamente são solicitados pela classe médica, é exposta no discurso do propagandista. No entanto, o entrevistado demonstra certo embaraço ao concluir que o comportamento da indústria farmacêutica não é errado, quando na verdade, não é proibido conforme o estabelecido pela resolução citada. $O$ uso da palavra 'errado' provoca uma reflexão sobre o que se entende por certo e errado quando, na realidade, determinado assunto é permitido ou proibido por uma lei, sendo esta passível de influência por diversos agentes no ato de sua elaboração. Com isso, leva-se a crer numa ética condicionada, ou seja, ao invés de ser algo inerente aos indivíduos, o que ele tem como certo e errado é baseado em uma resolução, que pode ser modificada diversas vezes, como é caso da própria RDC N 96/2008, dado que esta é uma atualização da RDC Nº 102/2000.

Novamente o médico é visto como ator dominante e que dispõe de poder nessa relação, como relata E3:

"Com alguns a entrada é mais fácil, até porque são mais, vamos supor, humanizados, então te recebem mais como amigos. Outros são mais realmente sérios, profissionais . É... [pausa longa] ...as dificuldades são com os concorrentes, as vezes existem produtos similares que tem um preço mais abaixo que o seu, então 
você tem que conquistar o médico, mostrar que a qualidade é indiscutível". (E3, grifo nosso).

O entrevistado revela um olhar pejorativo em relação à classe médica ao separá-la em dois grupos, um classificado como "mais humanizado" e "amigo", e outro classificado como "sério" e "profissional", significando que médicos sérios e profissionais são uma potencial dificuldade. Contudo, adiante, ele se contradiz ao enxergar os concorrentes que praticam preços melhores como um obstáculo na sua relação com a classe médica; já que não necessariamente um preço menor queira dizer que o remédio da concorrência seja ineficaz e que há possibilidade de diversas faixas de preços, o que, aumentaria a acessibilidade à saúde por parte de consumidores com menor poder aquisitivo e, por consequência, aumentaria também o índice de bem-estar geral. $O$ entrevistado necessita, portanto, cooptar o médico a prescrever o medicamento de seu laboratório, com o argumento de que este possui incontestável qualidade, mesmo tendo consciência de que se trata de um produto similar.

Os representantes farmacêuticos têm como alvo os profissionais que estão inseridos nas áreas médicas de maior potencial de venda dos produtos farmacêuticos. Afinal, é o médico que possui a competência de prescrição dos medicamentos, que possivelmente serão transformadas em vendas, ou seja, um dos principais canais para se chegar ao consumidor final. Alarmante é o fato de que a preocupação principal da indústria farmacêutica não seja levar o medicamento e/ou fazê-lo acessível a quem precisa, mas sim, vender seu produto. Entretanto, consciente do que foi dito, o entrevistado busca suavizar seu discurso e faz uma autocorreção ao mencionar que a preocupação é a necessidade do paciente, demonstrando contradição e incoerência com o restante da fala. As patologias, portanto, são vistas como oportunidades de negócio, corroborando a medicalização da saúde exposta por Blank e Brauner (2009), como é visto na afirmação de E4:

"A estratégia é a seguinte: sempre nos primeiros contatos ver o que o médico tem de tendência prescritiva. Vamos supor: um médico trata muito mais patologia do que faz estética (referindo-se a um dermatologista), então a gente... [pausa longa] ...nós vamos ter uma abordagem voltada pra necessidade dele, né?! Na verdade, necessidade do paciente dele, adequando o nosso produto ao mercado dele. Então a preocupação primária da empresa e da grande maioria dos representantes é trabalhar a necessidade junto com a oportunidade, esse seria o maior ponto de negociação. [...] Então assim, a gente busca sempre trabalhar de acordo com o mercado, onde o cliente tem maior potencial". (E4).

É interessante observar que em toda fala do entrevistado, faz-se o uso da primeira pessoa do plural, manifestando o lócus de enunciação e intradiscursividade com o discurso da indústria farmacêutica. Revela-se, assim, o 
discurso corporativo, ou seja, as intenções passadas pelo agente por detrás do representante, a empresa, pois replica seu discurso hegemônico, o que talvez não seja o discurso pessoal - se é que ele tem alguma opinião em relação a esse tipo de atitude, ou comportamento; ou ainda, talvez tenha escolhido (consciente ou inconscientemente) retirar-se de um lugar de escolha para evitar possíveis conflitos morais.

\section{Conclusões}

Com base nos aspectos da relação assimétrica entre o complexo médico-industrial e a sociedade, na qual prevalecem os interesses da indústria e da classe médica em detrimento do bem-estar do paciente, o objetivo desta pesquisa foi analisar se as práticas comerciais da indústria farmacêutica atendiam ao estabelecido pela RDC $N^{\circ}$ 96/2008 da ANVISA.

Partiu-se da premissa de que os representantes farmacêuticos conheciam as determinações da Resolução, escolhendo levá-la ou não em consideração durante o processo de prospecção de médicos, em concordância com a distribuição do remédio de seu empregador, em detrimento da concorrência. Contudo, observou-se que o discurso dos representantes farmacêuticos possui diversos aspectos em comum, como era esperado em indivíduos ocupantes da mesma profissão, mas nenhum desses aspectos parece ser ligado às decisões conscientemente tomadas em relação à Resolução no estabelecer e consolidar suas relações com os médicos. Na verdade, os entrevistados possuíam pouco ou nenhum conhecimento sobre a resolução que estabelece os limites de atuação. Logo, percebeu-se a impossibilidade de analisar práticas conscientes por parte dos representantes farmacêuticos, uma vez que desconheciam a Resolução.

Observou-se, contudo, um padrão desconcertante no que tange à conduta desses profissionais, dada a insciência em relação às regulações do seu setor: se o representante farmacêutico afirma não ter conhecimento da legislação, ele também não tem conhecimento do limite de seu comportamento. Ou seja, não é capaz de articular suas estratégias de convencimento, como mostrado pelos entrevistados, em concordância com o estabelecido, dando margem à existência de condutas que, mesmo inconsequentes, como observado, seriam no mínimo não-éticas, se comparadas ao que a resolução determina.

Já que a resolução foi publicada no Diário Oficial da União, o fato de os representantes não terem ciência das limitações que ela impõe à execução de sua atividade-fim pode ser um indício de que essa empresa deliberadamente escolheu não notificá-los, como modo de impedir mudanças num processo de cooptação que já havia se consolidado com resultados em conformidade aos seus objetivos. $O$ achado é referendado pelo fato de nenhum deles falar sobre qualquer tipo de fiscalização em relação ao cumprimento do determinado pela resolução, ou demonstrar qualquer tipo de receio quanto a possível não conformidade de seus atos e consequências dessa possibilidade. Além disso, 
percebe-se o poder do discurso corporativo, capaz de influenciar a ação e não-ação dos indivíduos, sendo toda essa relação composta de discursos sobrepostos, ou seja, interdiscursividade e intradiscursividade: inicialmente se tem o discurso da empresa que sobrepõe-se ao discurso do propagandista, que por sua vez, sobrepõe-se ao discurso do médico; e, que, por fim, sobrepõe-se ao discurso do paciente.

A principal limitação presente nesse estudo refere-se à compreensão de significados presentes exclusivamente nos discursos de representantes farmacêuticos de uma única organização. Desse modo, sugere-se, para pesquisas futuras, a continuação dos estudos realizados, objetivando analisar a perspectiva de outros agentes envolvidos nessa relação, como, a classe médica e a sociedade, ou mesmo a perspectiva de representantes de outras empresas do setor, como forma de buscar maior compreensão sobre o possível desconhecimento da Resolução, e se isso é uma tendência desse mercado, se é prática comum, ou se apenas uma característica isolada, presente nos discursos dos propagandistas da organização estudada.

\section{Referências}

ABBASI, K.; SMITH, R. No more free lunches. BMJ: British Medical Journal, p. 326-1155, 2003.

ABDALLA, M. M. Do Abstrato ao Concreto: Analisando a Multiplicação das Mercadorias Fictícias de Karl Polanyi a partir de um Contexto Latino Americano. In:XL Encontro da ANPAD - EnANPAD, 40. Anais... Costa do Sauípe/BA, 2016.

ABDALLA, M. M.; ALTAF, J. G. Análise Crítica do Discurso em Administração/Gestão: sistematização de um framework metodológico. Revista ADM. MADE, v. 22, n. 2, p. 35-47, 2018

ANDERSON, C.; BERDAHL, J. L. The experience of power: examining the effects of power on approach and inhibition tendencies. Journal of personality and social psychology, v. 83, n. 6, p. 1362, 2002.

ANVISA. Resolução RDC $\mathbf{n}^{\circ}$ 96, de 17 de dezembro de 2008. Ministério da Saúde - MS. Agência Nacional de Vigilância Sanitária - Anvisa. Disponível em: <http://portal.anvisa.gov.br/legislacao\#/visualizar/28284>. Acesso em: 23 mar. 2017.

APPLBAUM, K. Pharmaceutical marketing and the invention of the medical consumer. PLoS Medicine, v. 3, n. 4, 2006.

BARLEY, S. R. Building an institutional field to corral a government: A case to set an agenda for organization studies. Organization Studies, v. 31, n. 6, p. 777-805, 2010.

BARROS, A.; CARRIERI, A. de P. O cotidiano e a história: construindo novos olhares na administração. RAE-Revista de Administração de Empresas, v. 55, n. 2, p. 151-161, 2015.

BASTOS, V. D. . Inovação farmacêutica: padrão setorial e perspectivas para o caso brasileiro. BNDES Setorial, Rio de Janeiro, v. 22, p. 271-296, 2005.

BLACK, I. Pharmaceutical marketing strategy: Lessons from the medical literature. Journal of Medical Marketing, $v$. 5, n. 2, p. 119-125, 2005

BLANK, D. M. P.; BRAUNER, M. C. C. . Medicalização da saúde: biomercado, justiça e responsabilidade social. JURISRevista da Faculdade de Direito, v. 14, p. 7-24, 2009.

BOMFIM, D. E. da C.; PEREIRA, J. L. B. Os Médicos e a Indústria Farmacêutica. Gazeta Médica da Bahia, v. 74, n. 2, 2008.

BRANDÃO, H. H. N. Introdução à análise do discurso. 2ª . Edição revisada: Campinas, SP: Editora da UNICAMP, 2004. 
"AJUDE AÍ DOUTOR!" PODER, HEGEMONIA E COOPTAÇÃO NA BIG PHARMA À LUZ DA ANÁLISE CRÍTICA DO DISCURSO

BRANDÃO, I. A. P. Validação do sistema de água purificada na indústria farmacêutica. [TCC-Especialização]. Rio de Janeiro: Instituto de Tecnologia em Fármacos/Farmanguinhos, Fundação Oswaldo Cruz, 2015.

BRASIL. Decreto-Lei $\mathbf{n}^{\mathbf{0}} \mathbf{4 . 6 5 7 / 1 9 4 2}$. Lei de Introdução às Normas do Direito Brasileiro.

BRESSER-PEREIRA, L. C. Assalto ao Estado e ao mercado, neoliberalismo e teoria econômica. Estudos avançados, v. 23, n. 66, p. 7-23, 2009.

BRETT, A. S.; BURR, W.; MOLOO, J. Are gifts from pharmaceutical companies ethically problematic?: a survey of physicians. Archives of internal medicine, v. 163, n. 18, p. 2213-2218, 2003.

CARVALHO, K. M. D.; TEIXEIRA, R. M. A influência de estratégias promocionais na adoção de novos produtos: o caso da indústria farmacêutica. Caderno de pesquisas em Administração, v. 9, n. 1, p. 61-74, 2002.

CONNORS, A. L. Big bad pharma: an ethical analysis of physician-directed and consumer-directed marketing tactics. Alb. L. Rev., v. 73, p. 243, 2009.

COPEINSKI, E. E.; APPA, R. SER ÉTICO É UMA ESCOLHA POSSÍVEL. Qualis Sumaré-Revista Acadêmica Eletrônica, V. 11, n. 1, 2016.

CORRÊA, G. F.; OLIVEIRA, L. H. D. Os novos rumos da estratégia de marketing no mercado farmacêutico. Organizações Rurais \& Agroindustriais, v. 10, n. 3, 2008.

CORTELLA, M. S. Educação, Convivência e Ética: audácia e esperança!. Cortez Editora, 2015.

DANA, J.; LOEWENSTEIN, G. A social science perspective on gifts to physicians from industry. Jama, v. 290, n. 2, p. 252-255, 2003.

DAS, A. Pharmaceutical industry and the market: The case of Prozac and other antidepressants. Asian Journal of Psychiatry, v. 4, n. 1, p. 14-18, 2011.

DIJK, T. A. V. Discurso, Organizações e Sociedade. Farol-Revista de Estudos Organizacionais e Sociedade, v. 3, n. 7, p. 730-761, 2016.

DOS SANTOS, P. L. P. Mercantilização da saúde e cidadania perdida: o papel do sus na reafirmação da saúde como direito social. Revista da UNIFEBE, v. 1, n. 11, 2013.

FAIRCLOUGH, N. Discurso e mudança social (I. Magalhães, Trad.). Brasília: Universidade de Brasília, 2001.

FARIA, A.; ABDALLA, M. M. O que é (estratégia de) não mercado?. Organizações \& Sociedade, v. 21, n. 69, p. 315333, 2014.

FLEMING, P.; SPICER, A. Power in management and organization science. The Academy of Management Annals, v. 8, n. 1, p. 237-298, 2014.

GULATI, R.; SYTCH, M. Dependence asymmetry and joint dependence in interorganizational relationships: Effects of embeddedness on a manufacturer's performance in procurement relationships. Administrative science quarterly, v. 52, n. 1, p. 32-69, 2007.

GIL, A. C. Como elaborar projetos de pesquisa. São Paulo: Atlas, 2002.

HARVEY, D. O neoliberalismo: história e implicações. São Paulo: Edições Loyola, 2008.

IRIGARAY, H. A. R.; CUNHA, G. X.; HARTEN, B. A. Missão organizacional: o que a análise crítica do discurso revela?. Cadernos EBAPE. BR, v. 14, n. 4, p. 920-933, 2016.

KATZ, D.; CAPLAN, A. L.; MERZ, J. F. All gifts large and small. American Journal of Bioethics, v. 3, n. 3, p. 39-46, 2003.

KOMESAROFF, P. A.; KERRIDGE, I. H. Ethical issues concerning the relationships between medical practitioners and the pharmaceutical industry. Medical Journal of Australia, v. 176, n. 3, p. 118-121, 2002.

LEVITT, T. Exploit the product life cycle. Harvard Business Review, 1965.

LIMA, L. C.; DE AMORIM, W. A. C.; FISCHER, A. L. Da Racionalidade Instrumental para a Substantiva: explorando possibilidades da Gestão De Clima Organizacional. Teoria e Prática em Administração (TPA), v. 5, n. 1, p. 159-182, 2015.

MANCEBO, D., OLIVEIRA, D. M., FONSECA, J. G. T. D., \& SILVA, L. V. D. Consumo e subjetividade: trajetórias teóricas. Estudos de Psicologia, v. 7, n. 2, p. 325-332, 2002. 
MARCONDES, D. Textos básicos de ética: de Platão a Foucault. Zahar, 2007.

MARQUES FILHO, J. A dimensão bioética dos conflitos de interesses na relação entre médico e indústria farmacêutica. Revista Brasileira Clínica Médica, v. 8, n. 2, p. 148-53, 2010.

MASSUD, M. Conflito de interesses entre os médicos e a indústria farmacêutica. Revista Bioética, v. 18, n. 1, 2010.

MENDONÇA, A. L. O.; CAMARGO JR, K. R. Medical-industrial and medical-financial complex: the epistemological and axiological sides of the balance. Physis: Revista de Saúde Coletiva, v. 22, n. 1, p. 215-238, 2012.

MOLINARI, G. J. P.; MOREIRA, P. C. dos S.; CONTERNO, L. de O. A influência das estratégias promocionais das indústrias farmacêuticas sobre o receituário médico na Faculdade de Medicina de Marília: uma visão ética. Revista Brasileira Educação Médica, v. 29, n. 2, p. 110-118, 2005.

MORESI, E. Metodologia da pesquisa. Brasília: Universidade Católica de Brasília, 2003.

NOGUEIRA, C. A análise do discurso. Métodos e técnicas de avaliação: novos contributos para a pratica e investigação. Braga: CEEP, 2001.

NYE, J. S. Soft power: The means to success in world politics. PublicAffairs, 2004.

ORLANDI, E. P. Análise de discurso: princípios e procedimentos/Eni P. Orlandi-8 ${ }^{a}$ Edição, Campinas, SP: Pontes, 2009.

PÊCHEUX, M. Semântica e discurso. Uma crítica à afirmação do óbvio, v. 3, 1988.

PORTAL BRASIL. Produção industrial cresce pelo $4^{\circ}$ mês consecutivo. 2016. Recuperado em 20 de dezembro de 2016, de: http://www.brasil.gov.br/economia-e-emprego/2016/08/producao-industrial-cresce-pelo-4mes-consecutivo

RAMOS, F. C. Relacionamento com médicos como estratégia de marketing da indústria farmacêutica. 2010. Tese de Doutorado.

REIS, C.; CAPANEMA, L. X. D. L.; PALMEIRA FILHO, P. L.; PIERONI, J. P.; SOUZA, J. O. B. D.; SILVA, L. G. D. (2009). Biotecnologia para saúde humana: tecnologias, aplicações e inserção na indústria farmacêutica. BNDES Setorial, n. 29, p. 359-392, 2009.

RIBEIRO, L. G.; JURUENA, M. F. Médicos, Indústria Farmacêutica e Propaganda: que relação é essa?. Saúde \& Transformação Social/Health \& Social Change, v. 4, n. 1, p. 3-10, 2013.

RIOS, L. E.; MORAES, V. A. Uma abordagem ética do conflito de interesses na área de saúde. Revista BioethikosCentro Universitário São Camilo, v. 7, n. 4, p. 398-403, 2013.

ROSELLE, L.; MISKIMMON, A.; O'LOUGHLIN, B. Strategic narrative: A new means to understand soft power. Media, War \& Conflict, v. 7, n. 1, p. 70-84, 2014.

SANTOS, J. S. D.; BLIACHERIENE, A. C.; UETA, J. A via judicial para o acesso aos medicamentos e o equilíbrio entre as necessidades e desejos dos usuários do Sistema de Saúde e da indústria. BIS. Boletim do Instituto de Saúde, v. 13, n.1, p. 66-75, 2011.

SANVITO, W. L. Indústria farmacêutica: uma abordagem crítica. Revista da Sociedade Brasileira de Clínicas Médicas, v. 10, n. 4, p. 346-50, 2012.

SILVA, D. Teorias de mercado e regulação: por que os mercados e o governo falham?. Cadernos EBAPE. br, v. 8, n. 4, p. 644-660, 2010.

SILVA, E. R. da; GONÇALVES, C. A. Possibilidades de incorporação da análise crítica do discurso de Norman Fairclough no estudo das organizações. Cadernos EBAPE. BR, v. 15, n. 1, p. 1-20, 2017.

URDAN, A. T. O executivo de vendas no Brasil e a intenção de comportamento antiético: parte final. 2005.

URDAN, F. T.; URDAN, A. T. Gestão do composto de marketing. São Paulo: Atlas, 2013.

VIEIRA, M. M. F.; MISOCZKY, M. C. Instituições e poder: explorando a possibilidade de transferências conceituais. Organizações, cultura e desenvolvimento local: a agenda de pesquisa do Observatório da Realidade Organizacional. Recife: Editora Universitária UFPE, 2003.

VINUTO, J. A amostragem em bola de neve na pesquisa qualitativa: um debate em aberto. Temáticas, v. 22, n. 44, 2014.

WAZANA, A. Physicians and the pharmaceutical industry: is a gift ever just a gift?. Jama, v. 283, n. 3, p. 373-380, 2000. 
"AJUDE AÍ DOUTOR!" PODER, HEGEMONIA E COOPTAÇÃO NA BIG PHARMA À LUZ DA ANÁLISE CRÍTICA DO DISCURSO 
RAQUEL DE SOUZA CORRÊA, MÁRCIO MOUTINHO ABDALLA 
"AJUDE AÍ DOUTOR!" PODER, HEGEMONIA E COOPTAÇÃO NA BIG PHARMA À LUZ DA ANÁLISE CRÍTICA DO DISCURSO 